\title{
The virtual toolkit of digital instruction and its application in digital work forms
}

\author{
György Molnár, David Sik \\ Department of Technical Education \\ Budapest University of Technology and Economics \\ Budapest, Hungary \\ E-mail: molnargy@eik.bme.hu, siktdavid@gmail.com
}

\begin{abstract}
The COVID-19 pandemic had a special impact not only on lifestyles and work forms, but on the education process itself. The exigency occurring in a relatively fast manner required quick adaptation of methodological practices and learning support solutions. The Web 2.0 became a crucial provider of technological support services, which resulted in the increased prevalence of written and oral culture in education along with that of the creative-participatory effort and activity of students [1]. Our study explores and introduces digital tools and methods providing the most effective and state of the art support to all participants in the digitalized education arena including teachers, students and parents.
\end{abstract}

Keywords-ICT based framework, Ms Teams, TeamLink, Skpye, Zoom, WebEx, LMS, Webinar, Discord

\section{INTRODUCTION}

"Due to the amortization of knowledge in the constantly changing world of today's information society, the new phenomena of the paradigm shift in pedagogy are clearly outlined. The ever-changing economic and social environment also plays a significant role" [4]. This process is clearly supported by the rapid development of digitalisation, the penetration of the Internet and Web 2.0 and new media tool systems. Consequently, the traditional educational environment will be converted into a virtual and digitalized space without spatial or temporal obstacles. The respective learning environment is improved as a result of the shared and active participation of students and teachers. The given schemes contribute to an open educational context [2] assuring the formation and development of problem solving thinking skills and providing the option of mobile learning. Due to the latter features individualized and self-regulated learning environments requiring the development of personalized learning strategies can emerge (Attwell, 2007) [3]. In the era of digital work schedules such solutions entailing digital platforms and virtual and three-dimensional presentation technologies suitable for the improvement of cognitive skills of learners can gain a greater appreciation [4] [6] [7] [8-14].

\section{ONLINE DIGITAL TOOLS AND PLATFORMS}

The VUCA phenomenon compelled fast response from educational systems and all participants in the educational arena during the pandemic. This meant the immediate application of on-line digital support systems in addition to the technological innovation along with the formation of a new methodological culture on part of the pedagogues. While both factors were hard to handle, the best individual solutions developed both in the mezo and micro-spheres of the education process. We would like to introduce a few examples from such set of solutions, digital tools including those typical technological and digital framework systems and services, which proved to be most successful in the past months [19] [20] [21] [22].

\section{Ms Teams}

The Microsoft Teams framework system is a cloud based electronic learning and learning management system fulfilling various and highly diverse functions in return for a given fee. It has a web and work station based version, and the latter features more functions. During the first stage of the COVID-19 epidemic the Teams made available to education institutions free of charge was one of the most popular digital educational platforms. The Teams is suitable for the handling of various school groups, classes, chat channels, and on-line meetings in real time and recording and storing them on video. A click on the given courses reveals options for shared tasks, information sets, homework, feedback, and electronic tests. Several applications including the Polly voting system and the interactive Freehand Invision digital notes can be integrated into the respective courses. Other options include screen sharing and the delivery of virtual presentations [15] [16] [17] [18]. During the on-line lesson students and instructors as well can be present via camera pictures, microphone, and their own background image. The system can manage several calls and on-line meetings simultaneously. Figure 1 shows the opening page of the work station based Teams program with the tiles representing the various course group options. 


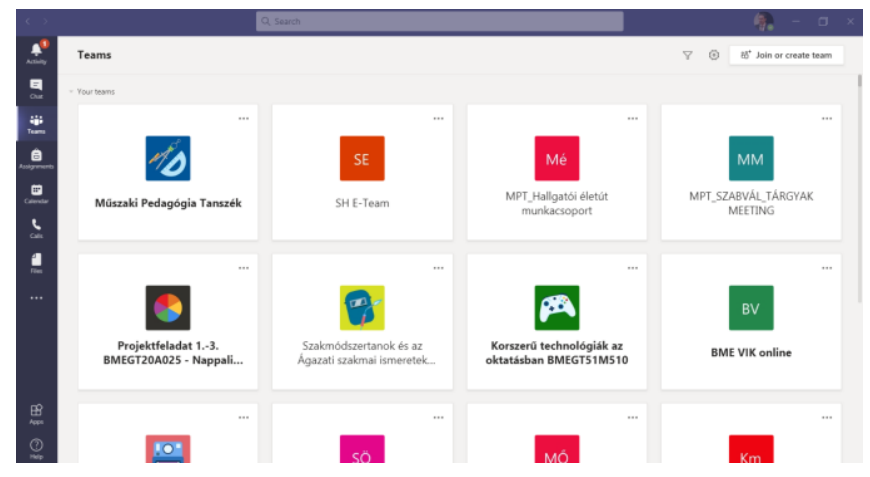

Fig. 1. Teams

\section{A. Skype}

Skype was introduced in 2003 as a peer-to-peer based voice call application. In 2011 it was acquired by Microsoft and during the last decade it became a complex telecommunication application including text and video chat, video conferences, meetings up to 50 participants, voice calls, file sharing, etc. between computers, tablets, smartphones or by using web browsers, Alexa and Xbox.

Skype supports the most important operating systems as Windows, macOS, Linux, Android, iOS, Windows Phone, HoloLens, Xbox One and it is available in 108 languages. Skype operates in the freemium business model. Many of its features are free, but the users have to pay for some extra features. For example the calls involving the global telephony network e.g. calling US mobile and landlines starts from 2.4 Eurocents/min, calling UK mobiles and landlines starts from 2.1 Eurocents/min.

Skype developed many products: Skype Manager to manage family, groups and business communication; Skype for content creators when Skype becomes available for integration into podcasts or live streams; finally Skype for business which has already been integrated into Microsoft Teams.

Skype supports many features including audio and video calling, smart messaging, screen sharing, call recording and live subtitles, call phones, private encrypted conversations. It is also possible to get a local phone number connecting to Skype or to send SMS from Skype. There are many comfort features also such as location sharing, background effects on video calls, real-time translation of voice calls, video calls and instant messages, call forwarding, voicemail, Cortana smart replies, etc.

Skype has become one of the most popular telecommunication applications, helping to organize meetings from all over the world, connecting friends and family members on different locations, and supporting the education process. In the beginning it was used for education mostly individually, the main target group was the language learners.

In the beginning of the 2010s Skype in the Classroom was introduced as a free global community that enables thousands of teachers to inspire the next generation of global citizens by participating in one of our live learning experiences. Due to the COVID-19 pandemic Skype was used as one of the online telecommunication platforms for distance learning, and according to the statistics, there was a $70 \%$ increase in the number of users and a $220 \%$ increase in the Skype-to-Skype calls.

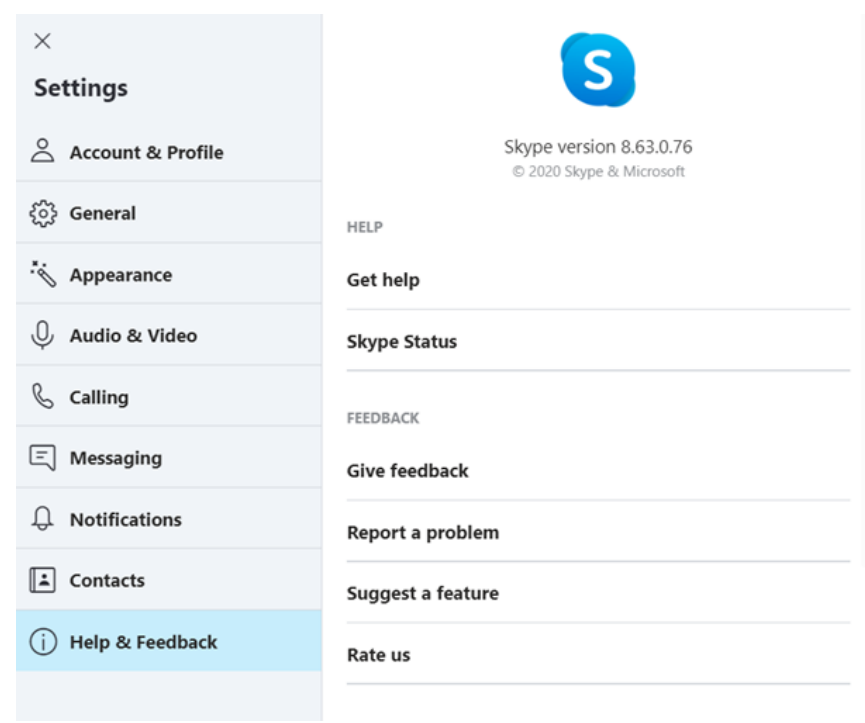

Fig. 2. Skype

\section{B. WebEx}

Webex was founded in 1995, but the software itself was launched in 1999 and it allowed up to 6 participants to meet in real-time to share presentations, documents, and software applications. It was a free service including advertisements, but it was possible to upgrade to an advertisement-free version.

The company was acquired by the Cisco Systems in 2007. Since then Webex has been providing solutions such as video conferencing, team collaboration, online event management, cloud calling, online training management, remote support management, contact centre, hardware (Board, Room Kit etc).

Webex has two main software: Webex Meetings and Webex Teams. Both software are available for Windows, iOS and Android devices (also as browser add-ons). In the context of Webex Meetings there are two main meeting types: Webex Meeting (scheduled), Webex Personal Room Meeting.

There are four main roles in a meeting: host, panelist, presenter and attendee. When a meeting is initiated by a host, he/she can assign roles to the other participants (attendees).

During a meeting, it is possible to share video and/or audio, and to chat in text. It is possible to transfer files between the participants, also to share content (window), share web browser screen, share multimedia (URL) or share the meeting window itself. During a sharing it is possible to annotate the screen by drawing, or writing on it. Webex also supports recording locally or in the cloud, virtual background, music mode, connecting to a nearby device, 
closed capturing and it is also possible to join Webex meetings by calling real global call with numbers. Webex can be integrated to web browsers or even into Microsoft Teams or other environments including email notifications. Even the easiest way to join a meeting is by using its 9-digits meeting number.

Another useful feature is the polling. The host can create one or more questions as a poll for the participants. Webex supports three question types: multiple choice single answer, multiple choice multiple answer and short answer. The questions might have time limits to answer them, then they are evaluated automatically.

Webex provides a personal plan and three different plans for companies, depending on the size of the company or teams with different features and limitations. The personal plan includes up to 100 participants in each meeting. The meeting can last up to 50 minutes, but a host can initiate an unlimited number of meetings. Recently Webex for Education was also introduced to support distance learning. This includes collaboration for classrooms supporting the cognitive aspects and integration into learning management systems.

Due to the COVID-19 pandemic Webex was used as one of the online telecommunication platforms, and according to the statistics in April 2020, they had 500 million meeting attendees, and that equaled to 25 billion meeting minutes.

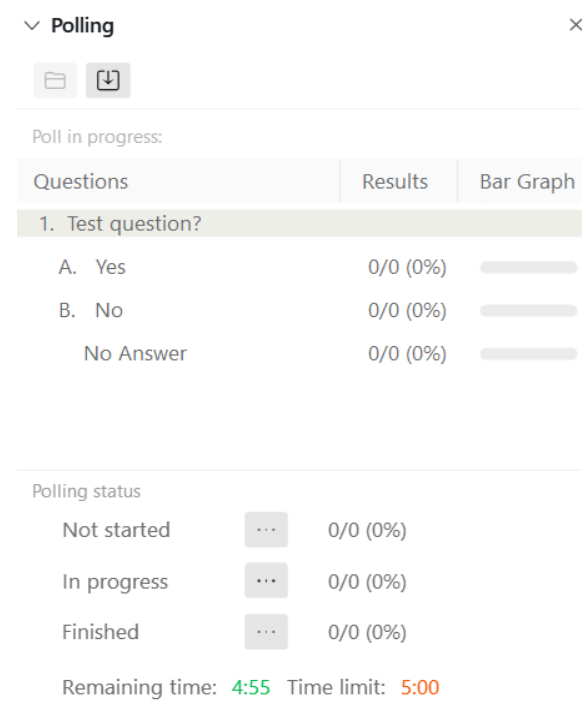

Fig. 3. Polling in Webex

\section{Zoom (ZOOM)}

While the system previously had been facing data protection (GDPR) problems, such issues have been eliminated by the present. The free of charge version provides the option of a 40 minute webinar, while unlimited time sessions along with more administrative organising possibilities become available after paying a charge. It is a stable, reliable surface displaying the camera image of all participants at once. The system is suitable for the establishment of separate digital rooms along with screen sharing and the recording of video. The Zoom facilitates the formation of individual private and public meeting rooms. Figure 4 shows the opening surface of a private room with the available tool and device options.

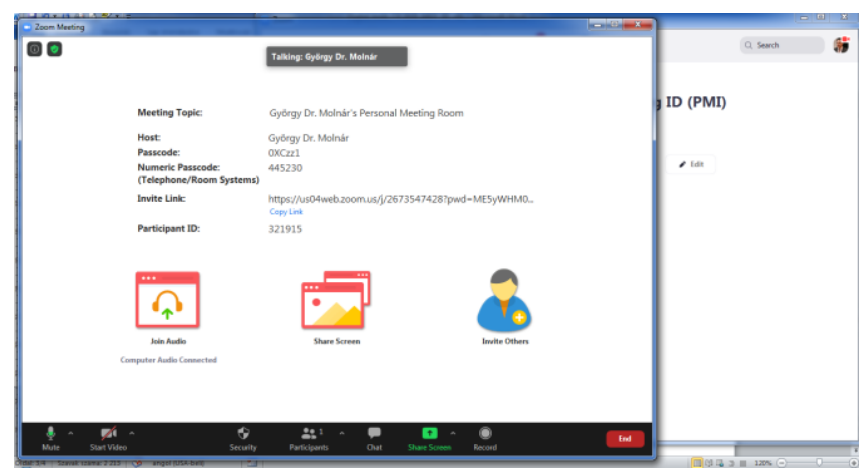

Fig. 4. Zoom

\section{Additional digital platforms}

In addition to the abovementioned effective digital framework systems and surfaces such platforms should be mentioned as the Discord, the TeamLink, the Google Classroom, the Google Meet, the Neptun Meet Street (NMS), the Neo LMS, the Jitsi Meet, along with such webinar applications as ACP and Moodle Webinars. The latter options have been deployed in various levels of the educational process.

\section{SUMMARY}

In our study we attempted to highlight globally used digital platforms and framework systems determining the foundations of current on-line digital instruction schemes. The respective support systems and methodological solutions can provide useful guidelines for society at large. The given options are being utilized during the current second wave of the COVID-19 epidemic. Consequently, such repertoire should be adapted to the respective individual needs in the near future.

\section{ACKNOWLEDGMENT}

This study was prepared by assistance provided by the Bolyai János Research Stipend.

\section{REFERENCES}

[1] Blees, I., \& Rittberger, M. (2009).Web 2.0 learning environment: concept, implementation, evaluation. Elearning papers, 15.

[2] Kerres, M. (2007). Microlearning as a challenge to instructional design. In Hug, T., \& Lindner, M. (ed.): Didactics of microlearning. münster: waxmann

[3] Attwell, G. (2007). Personal learning environments - the future of elearning? Elearning papers, 2 (1), 1-8.

[4] G. Molnár and D. Sik, "Supporting Learning Process Effectiveness with Online Web 2.0 Systems on the basis of BME Teacher Training," 2018 9th IEEE International Conference on Cognitive 
Infocommunications (CogInfoCom), Budapest, Hungary, 2018, pp. 000337-000340

[5] Molnár, G. \& Z., Szűts \& Biró, K. (2018). "Use of Augmented Reality in Learning." Acta Polytechnica Hungarica. 15. 209-222.

[6] P. Baranyi, A. Csapo, Gy. Sallai, Cognitive Infocommunications (CogInfoCom), Springer International Publishing Switzerland, 2015.

[7] Kovari Attila, "CogInfoCom Supported Education: A review of CogInfoCom based conference papers," 2018 9th IEEE International Conference on Cognitive Infocommunications (CogInfoCom), 2018. pp. 233-236.

[8] Berki B,, "2d advertising in 3d virtual spaces," Acta Polytechnica Hungarica, vol. 15, no. 3, pp. 175-190, 2018.

[9] Horvath I., Sudar A., "Factors contributing to the enhanced performance of the maxwhere $3 \mathrm{~d}$ vr platform in the distribution of digital information," Acta Polytechnica Hungarica, vol. 15, no. 3, pp. 149-173, 2018.

[10] Lampert B., et al., "MaxWhere VR-learning improves effectiveness over clasiccal tools of e-learning," Acta Polytechnica Hungarica, vol. 15, no. 3, pp. 125-147, 2018.

[11] Horváth I., "Evolution of teaching roles and tasks in VR/AR-based education," 2018 9th IEEE International Conference on Cognitive Infocommunications (CogInfoCom), 2018. pp. 355-360.

[12] Biró K., et al. "The effects of virtual and augmented learning environments on the learning process in secondary school," 2017 8th IEEE International Conference on Cognitive Infocommunications (CogInfoCom), 2017. pp. 371-376.

[13] A. D. Kovács; Z. Kvasznicza, "Use of 3D VR environment for educational administration efficiency purposes," 2018 9th IEEE International Conference on Cognitive Infocommunications (CogInfoCom), 2018. pp. 361-366.

[14] V. Kövecses-Gösi, "Cooperative Learning in VR Environment," Acta Polytechnica Hungarica, vol. 15, no. 3, pp. 205-224, 2018
[15] R. Pinter and S. M. Cisar, "Measuring Team Member Performance in Project Based Learning", Journal of Applied Technical and Educational Sciences, vol. 8, no. 4, pp. 22-34, 2018.

[16] T. Ujbányi, "Examination of eye-hand coordination using computer mouse and hand tracking cursor control," 2018 9th IEEE International Conference on Cognitive Infocommunications (CogInfoCom), Budapest, Hungary, 2018, pp. 353-354.

[17] E. Gogh and A. Kovari, "Examining the relationship between lifelong learning and language learning in a vocational training institution", Journal of Applied Technical and Educational Sciences, vol. 8, no. 1, pp. 52-69, 2018

[18] A. Csapo, I. Horváth, P. Galambos and P. Baranyi "VR as a Medium of Communication: from Memory Palaces to Comprehensive Memory Management" In Cognitive Infocommunications (CogInfoCom), 2018 9th IEEE International Conference, Budapest, 2018, pp. 389-394.

[19] I. Horváth: "Innovative engineering education in the cooperative VR environment", In: Proceedings of 7th IEEE Conference on Cognitive Infocommunications. Wrocław, Poland, 2016. pp. 359-364

[20] I. Petkovics, "Digital Transformation in Higher Education", Journal of Applied Technical and Educational Sciences, vol. 8, no. 4, pp. 77-89, 2018 .

[21] J. Katona, T. Ujbanyi, G. Sziladi, A. Kovari: „Examine the Effect of Different Web-based Media on Human BrainWaves", 8th IEEE International Conference on Cognitive Infocommunications, Debrecen, 2017.

[22] Costescu, C. ; Rosan, A. ; Hathazi, A. ; Pădure, M. ; B., Nagy ; Kővári, A. ; Katona, J. ; Thill, S. ; Heldal, I.: Educational Tool for Testing Emotion Recognition Abilities in Adolescents, ACTA POLYTECHNICA HUNGARICA 17: 2 pp. 129-145., 17 p. 2020 